\title{
Detection of sexually transmitted infection and human papillomavirus in negative cytology by multiplex-PCR
}

\author{
Hyo-Sub Shim ${ }^{1 \dagger}$, Songmi Noh ${ }^{1 \dagger}$, Ae-Ran Park ${ }^{2}$, Young-Nam Lee ${ }^{1}$, Jong-Kee Kim ${ }^{3}$, Hyun-Jae Chung ${ }^{3}$, \\ Keum-Soon Kang ${ }^{1}$, Nam Hoon Cho ${ }^{1,4^{*}}$
}

\begin{abstract}
Background: The aim of this study was to determine the prevalence of human papillomavirus (HPV) and 15 species that cause sexually transmitted infections (STIs) in negative cytology. In addition, we compared the diagnostic performance of multiplex polymerase chain reaction (PCR) with widely available techniques used to detect HPV.

Methods: We recruited 235 women of reproductive age who had negative cytology findings in a liquid-based cervical smear. STIs were identified by multiplex PCR, and HPV genotypes by multiplex PCR, hybrid capture 2, and DNA microaray; discordant results were analyzed by direct sequencing.

Results: Approximately $96.6 \%$ of patients with negative cytology results were positive for pathogens that cause STIs. The pathogens most frequently detected were Gardnerella vaginalis, Ureaplasma urealyticum. The incidence of HPV in negative cytology was $23.3 \%$. Low-risk HPV infection was significantly correlated with Chalmaydia trachomatis, and high-risk HPV infection was significantly correlated with Group $\beta$ streptococcus. The analytical sensitivities of the multiplex PCR and DNA microarray were higher than $80 \%$, and the analytical specificity was nearly $100 \%$ for all tests.

Conclusions: Multiplex PCR yielded results that most of patients with negative cytology were positive for pathogens that cause STIs, and were more similar to that of DNA microarray, than that of hybrid capture 2 in terms of analytical sensitivity and prediction value of HPV infection.
\end{abstract}

\section{Background}

Sexually transmitted diseases (STDs) are fairly common in people of reproductive age; more than $50 \%$ of new STD infections occur in adolescents. However, only $50 \%$ to $80 \%$ of reportable STDs that occur in the United States are actually reported [1]. Testing for STDs can result in negative cytology, that is, laboratory test results that revealed reactive cellular change (RCC) or atypical squamous cells of undetermined significance (ASCUS). RCC or ASCUS is routinely screened for, but they are not associated with neoplasms or preneoplastic stages known as squamous intraepithelial lesions (SILs). RCCs

\footnotetext{
* Correspondence: cho1988@yuhs.ac

+ Contributed equally

'Department of Pathology, Yonsei University College of Medicine (Sungsanro 134), Seoul (120-752), South Korea

Full list of author information is available at the end of the article
}

are cytological alterations related to inflammation or irritation but, whether subtle or marked, are typically not associated with human papillomavirus (HPV) infection. Common features of RCCs include the formation of small perinuclear halos, mild nuclear enlargement or nuclear degeneration, hyperchromasia, cytoplasmic pseudokeratinization, cytoplasmic vacuolization, and notably a background of inflammation. The abnormal cytology of ASCUS can usually be distinguished from RCC, but does not meet all criteria of HPV-infected koilocytes [2].

With the exception of a few organisms that cause sexually transmitted infections (STIs) such as trichomoniasis or candidiasis, most inflammatory agents are only rarely recognized under the microscope and usually produce nonspecific cytopathic effects. For example, bacterial
C Biomed Central

C 2010 Shim et al; licensee BioMed Central Ltd. This is an Open Access article distributed under the terms of the Creative Commons Attribution License (http://creativecommons.org/licenses/by/2.0), which permits unrestricted use, distribution, and reproduction in any medium, provided the original work is properly cited. 
vaginosis (BV) is a leading cause of abnormal vaginal discharge as a sequel of gynecologic conditions, including endometritis, pelvic inflammatory disease (PID), postsurgical abortion, post-hysterectomy infection, and cervical intraepithelial neoplasia [3]. However, few attempts have been made to identify the etiologic organisms of $\mathrm{BV}$, and diagnoses have relied only on the presence of common "clue cells" detected in cervical swabs $[4,5]$. The prime manifestation of BV constitutes a massive microecologic alteration of vaginal flora characterized by decreased Lactobacillus spp., logarithmically-increased Gardnerella vaginalis, and the presence of potentially pathogenic bacteria, including Bacteroides, Peptococcus, Mobiliuncus, Ureaplasma urealyticum, and Mycoplasma spp. Mycoplasma spp. and $U$. urealyticum are most frequently detected in the vaginal tract [6], and are strongly associated with infertility, intra-amniotic infection, postpartum infection, and pelvic inflammatory disease (PID) [1-5]. The multiple strains of Mycoplasma are the only cell wall-deficient, membrane-bound organisms capable of independent self-replication: they include Mycoplasma hominis, M. genitalium, M. primatum, M. spermatophilum, and M. penetrans $[7,8]$.

Despite the fact that many pathogens are not detected by Gram stain, Gram-stained vaginal secretions are still accepted as the diagnostic gold-standard, rather than the culture of secretions. With the advent of advanced techniques such as those based on liquid-based cytology [9-13], it is now feasible to accurately and efficiently identify microorganisms in cervicovaginal swab specimens of asymptomatic patients with multiplex PCR or DNA chip. Although detection of infectious organisms is not the primary goal of cervical cytology, it can be an important component of screening in asymptomatic patients or subtle disease. We aimed to estimate the incidence of STIs in healthy women of reproductive age with negative cytologic findings by multiplex PCR and find any correlation of HPV infection with specific pathogens.

High-throughput technology including hybrid capture 2 (HC2) and DNA microarray has been currently adopted to detect HPV [14]. HC2 is a relatively easy method with high screening power, but it is unable to genotype or excludes low-risk HPV types. DNA microarray can identify specific genotypes, and can also detect co-infection in a single sample, but is laborintensive. Despite widely available high-throughput technology for the detection of microbes or HPV, few studies of STDs and HPV with high fidelity data exist due to lack of a gold standard. We therefore designed multiplex PCR assays to compare with the available methods of HC2 and HPV DNA microarray, and analyzed discordant results by direct sequencing.

\section{Methods}

A total of 235 married and sexually active women (mean age of $37.9 \mathrm{y}$; ages range 21 to 48 years) were recruited by the Department of cytopathology of Yonsei University College of Medicine for this study. Specimens collected from cervical liquid-based cytology medium were negative for intraepithelial lesions. Participants had no clinical STD symptoms that required a clinical visit, no history of STDs, and no abnormal Papanicolau tests (Pap smear) results. We also excluded patients with SIL or carcinoma, postmenopausal women, or those with previous operative or therapeutic history related to gynecologic disease. The study protocol was approved by the local institutional review board, and written informed consent was obtained from all participants.

\section{Multiplex-PCR for STI}

\section{Pretreatment and DNA Extraction of cervicovaginal swab specimens}

Cervix swab samples were collected from the posterior fornix and lavaged with $5 \mathrm{~mL}$ of sterile phosphate-buffered saline (PBS pH 7.4). PreservCyt specimens were tested by Seeplex ${ }^{\oplus}$ STI Master ACE Detection (Seegene, Seoul, Korea) or Seeplex ${ }^{\bullet}$ HPV4A ACE Screening (Seegene) within 1 month of collection. PreservCyt transport medium containing endocervical cells was vortexed vigorously, and $1-\mathrm{mL}$ samples were transferred into $1.5-\mathrm{mL}$ polypropylene tubes, each containing $1 \mathrm{~mL}$ of PreservCyt transport medium. The tubes were centrifuged at $13,000 \times g$ for $15 \mathrm{~min}$ at $20^{\circ} \mathrm{C}$. Supernatants were discarded, and each cellular pellet was suspended in $200 \mu \mathrm{L}$ of PBS. DNA was purified from these samples using the QIAamp DNA Mini Kit according to the manufacturers' instructions (Qiagen, Hilden, Germany). The quality and quantity of purified DNA was measured by spectrophotometry.

\section{Multiplex PCR}

Four primer sets were tested by STI multiplex PCR: Seeplex $^{\circ}$ STI Master Panel 1, 2, 3, and HPV4A ACE Screening. Panel 1 comprised of Neisseria gonorrhoeae (NG), Mycoplasma hominis (MH), Chlamydia trachomatis (CT), Ureaplasma urealyticum (UU), and M. genitalium (MG). Panel 2 comprised Trichomonas vaginalis (TV), Gardenerella vaginalis (GV), Bacteroides fragilis (BF), Mobiluncus curtisii (MC), and M. mulieris (MM). Panel 3 comprised Candida glabrata (CG), C. tropicalis (CT1), C. parapsilosis (CP), Group $\beta$ - streptococcus (GBS), and $C$. albicans (CA). Primers were designed such amplicon sizes differed sufficiently to be distinguished from each other; they ranged from $212 \mathrm{bp}(U U)$ to $635 \mathrm{bp}(C G)$ and the internal control was $981 \mathrm{bp}$. Optimized multiplex PCR was performed in $20 \mu \mathrm{L}$ reactions containing DNA template, primer mixture (final concentration of each primer, 3 pmole), $2 \times$ Master mix (Seegene, Korea) 
and $30 \mu \mathrm{g} / \mathrm{mL}$ of 8 -methoxypsoralen (MOP), which prevents contaminating DNAs from being amplified. PCR amplification was performed in an Applied Biosystem 9700 thermal cycler (Perkin-Elmer, Boston, MA, USA) with the following conditions: $94^{\circ} \mathrm{C}$ for $15 \mathrm{~min}$, followed by 40 cycles of $94^{\circ} \mathrm{C}$ for $30 \mathrm{sec}, 63^{\circ} \mathrm{C}$ for $1.5 \mathrm{~min}$ (or $60{ }^{\circ} \mathrm{C}$ for $1.5 \mathrm{~min}$ for HPV4A ACE Screening), and $72^{\circ} \mathrm{C}$ for $1.5 \mathrm{~min}$; and final extension at $72{ }^{\circ} \mathrm{C}$ for $10 \mathrm{~min}$. A DNA plasmid was added to the PCR reaction mixtures as an internal control to be co-amplified with the target DNAs collected from the clinical specimens. Sterile deionized water was included as a negative control in each batch of PCR reactions. Target organisms, target genes, accession numbers, and expected amplicon sizes are summarized in Additional File 1.

\section{Multiplex-PCR-}

HPV was detected with the Seeplex ${ }^{\oplus}$ HPV4A ACE screening kit for $14 \mathrm{HR}-\mathrm{HPV}$ types $(31,33,35,39,45$,

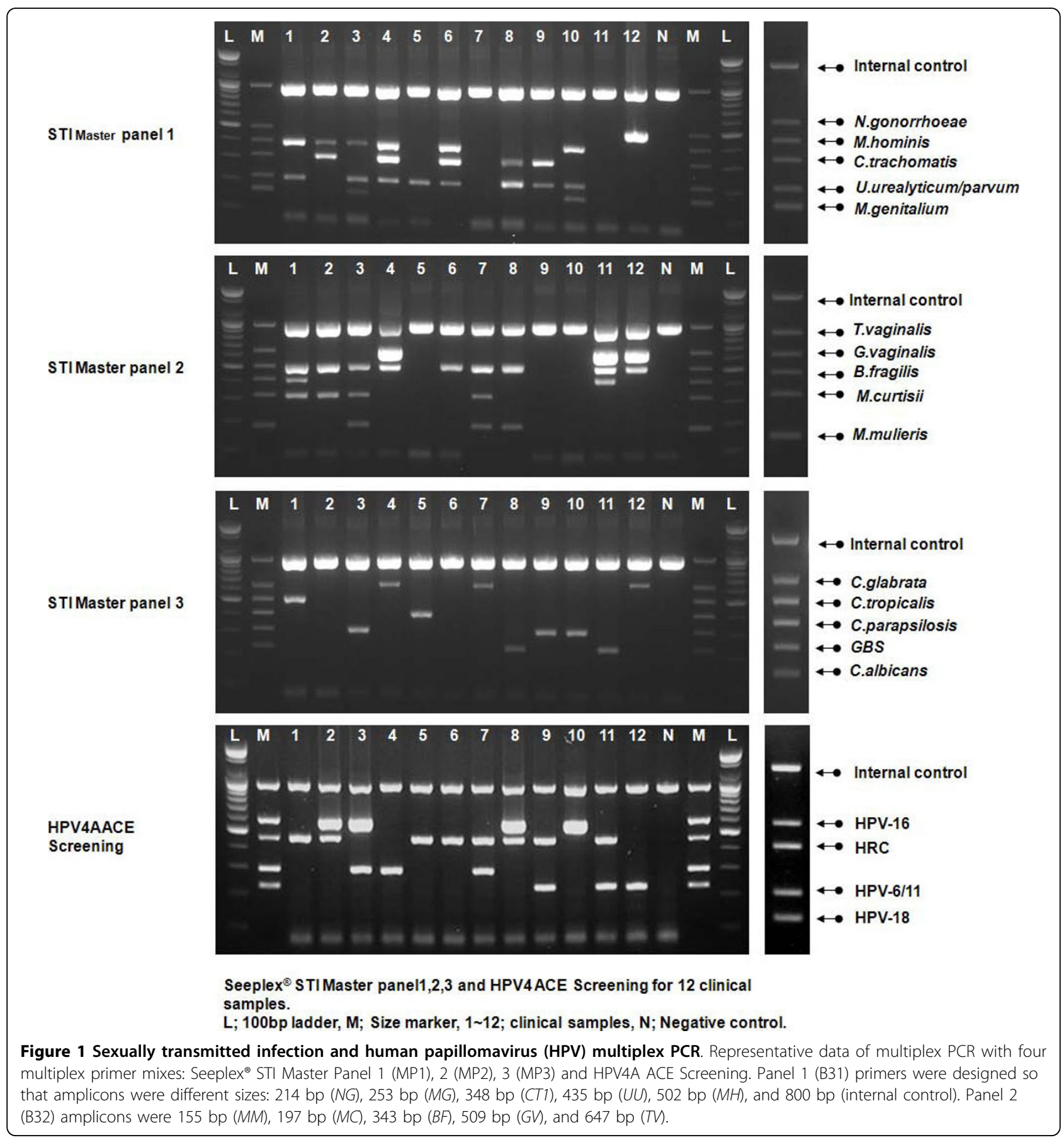


$51,52,56,58,59,66,67,68$, and 70) and 5 LR-HPVtypes $(6,11,42,43$ and 44$)$. In addition individual genotyping of HPV-16 and HPV-18 was performed with different multiplex primer mixtures.

\section{Hybrid capture 2 (HC2)}

HC2 HPV test (Digene, Gaithersburg, MD) was performed according to the manufacturer's instructions to detect HPV, starting from $4 \mathrm{~mL}$ of liquid cytology specimens. The HC2-13 HR probe cocktail detects HPV types-16, 18, 31, 33, 35, 39, 45, 51, 52, 56, 58, 59, and 68. Relative light unit/cut-off ratio between 1 and 2.5 relative light units was used as the threshold for a positive result.

\section{HPV Microarray}

We used an HPV genotyping DNA microarray (Biocore Ltd, Korea, Seoul) with multiple oligonucleotide probes of L1 sequence of 26 types of HPV (HR: 16,18, 26, 31, $33,35,39,45,51,52,56,58,59,66,68,69,73$ and 53 ; LR: 70, 6, 11, 32, 34, 40, 42, 43, 44, 54, 55, 57, 61 and 62). L1 consensus PCR products were hybridized to the probes on the microarray, and HPV genotypes were identified with a fluorescence scanner (GenPix 4000B, Axon Instruments Inc, CA) with a $532 \mathrm{~nm}$ laser for excitation of $\mathrm{Cy} 3$.

\section{DNA sequencing and cloning}

Discrepant results among the HC2, DNA microarray, and Seeplex ${ }^{\oplus}$ HPV4A ACE screening kit results were resolved by sequencing with the PGMY09/PGMY11 primer sets. PCR reactions $(20 \mu \mathrm{L})$ were performed with $2 \mu \mathrm{L}$ template DNA, $1 \mu \mathrm{M}$ of each primer, and 2x Master mix (Seegene, Korea). PCR amplification was carried out with an Applied Biosystem 9700 thermal cycler (PerkinElmer) with the following parameters: $94^{\circ} \mathrm{C}$ for $15 \mathrm{~min}$ followed by 40 cycles of $94^{\circ} \mathrm{C}$ for $30 \mathrm{sec}, 55^{\circ} \mathrm{C}$ for $1 \mathrm{~min}$, and $72^{\circ} \mathrm{C}$ for $1 \mathrm{~min}$, and a final extension at $72^{\circ} \mathrm{C}$ for $10 \mathrm{~min}$. The entire volume of each PCR reaction was run on a $2 \%$ agarose $/ 1 \times$ Tris-acetate-EDTA gel containing ethidium bromide. The 465-bp bands amplified by the PGMY09/PGMY11 primers were excised and transferred to $1.5-\mathrm{mL}$ tubes. DNA was extracted with the QiaexII gel extraction system (Qiagen, Valencia, CA) and eluted with $20 \mu \mathrm{L}$ Tris-EDTA buffer. The products were ligated into the pGEM-T Easy vector (Promega, Madison, WI), transformed into chemically-competent JM109 cells, and plated onto two Luria-Bertani (LB) plates containing ampicillin, isopropyl-D-thiogalactopyranoside, and 5-bromo-4-chloro-3-indolyl-D-galactopyranoside. DNA was extracted from the white colonies with the Qiaprep Spin kit (Qiagen) and sequenced with the ABI Big Dye Terminator v3.1 cycle sequencing kit and an ABI 377 sequencer (Applied Biosystems, Foster City, CA). Sequences were trimmed to exclude the amplification primer and vector sequences, and the resulting fragments were analyzed by BLAST http://www.ncbi.nlm.nih.gov/ blast. The top hit for each sequence was listed as the genotype.

\section{Statistical Analysis}

The agreement rate of kappa value with respect to a quantitative measure of agreement between assay methods was calculated. The sensitivity of the HPV multiplex PCR, HC2 or DNA microarray relative to DNA direct sequencing is the proportion of positive samples in each assay among sequencing positive samples, and the specificity is the proportion of negative samples in each assay among those negative samples in direct sequencing. The positive predictive value is the proportion of positive samples in DNA direct sequencing, among those positive samples in each assay, and the negative predictive value is the proportion of negative samples in sequencing among those negative in each assay.

\section{Results}

\section{Prevalence of STIs}

The overall prevalence of STIs in cervicovaginal samples of negative cytology, which was not clinically presented with BV, was $97.9 \%(230 / 235)$. Most patients of $84.9 \%(202 / 230)$ were co-infected by more than two microbes, whereas twenty-eight specimens were infected by a single agent (Fig. 1). Table 1 is an example to interpret data shown in Fig. 1 Most common agents we detected were $G V$ found in $88.1 \%$ of the samples (207/235), $U U$ in $63.0 \%(148 / 235)$, and GBS in $26.4 \%(62 / 235)$. The most frequently co-infected organism was observed in $M H$ infections, which was commonly observed with $U U(\mathrm{p}=0.000), M M(\mathrm{p}=$ $0.000), M C(\mathrm{p}=0.000)$, and $C T(\mathrm{p}=0.009)$. In addition, $G V$ and $M C(\mathrm{p}=0.014), M C$ and $M M(\mathrm{p}=$ $0.003), M G$ and $C A(\mathrm{p}=0.006)$, and $T V$ and $G B S(\mathrm{p}=$ 0.011 ) were similarly detected in the same samples.

\section{HPV infection status}

The incidence of HPV in negative cytology varied according to the assay used: multiplex-PCR, 24.7\% (58/ 235); HC2, 21.3\% (50/235); HPV chip, $22.6 \%$ (53/235). The HPV types which were most often detected included HPV-16 (PCR, 20.7\%; DNA Chip, 26.4\%) and HPV-18 (PCR, 8.6\%; DNA chip, 11.3\%). Less commonly detected HPV types included 51, 58, and 33 in the HR group, and 70 and 6 in the LR group. Eighteen LR-HPV types were detected by PCR (31.0\%), eight by DNA microarray (15.1\%), and 11 by direct sequencing. Infection with multiple genotypes was detected in 13 specimens $(22.3 \%)$ by PCR and 14 specimens $(26.4 \%)$ by DNA microarray. 
Table 1 Interpretation of data shown in Figure 1

\begin{tabular}{|c|c|c|c|c|}
\hline Sample \# & MP1 & MP2 & MP3 & HPV4AACE \\
\hline 1 & M. hominis, U urealyticum/parvum & $\begin{array}{l}\text { G. vaginalis, B fragilis, } \\
\text { M. curtisii }\end{array}$ & C. tropicalis & $\mathrm{HRC}$ \\
\hline 2 & M. hominis, C. trachomatis & G. vaginalis, M. curtisii & - & HPV-16 \\
\hline 3 & M. hominis, U urealyticum/parvum, M. genitlaium & $\begin{array}{l}\text { G. vaginalis, M. curtisii, } \\
\text { M. mulieris }\end{array}$ & GBS & HPV-16 \\
\hline 4 & $\begin{array}{l}\text { M. hominis, C. trachomatis, } \\
\cup \text { urealyticum/parvum }\end{array}$ & T. vaginalis, G. valginalis & C. glabrata & HPV-16, HPV 6/11 \\
\hline 5 & U urealyticum/parvum & - & C. parapsilosis & HRC \\
\hline 6 & $\begin{array}{l}\text { M. hominis, C. trachomatis, } \\
\cup \text { urealyticum/parvum }\end{array}$ & G. vaginalis & - & $\mathrm{HRC}$ \\
\hline 7 & - & $\begin{array}{l}\text { G. vaginalis, M. curtisii, } \\
\text { M. mulieris }\end{array}$ & C. glabrata & HRC, HPV-6/11 \\
\hline 8 & C. trachomatis, U urealyticum/parvum & G. vaginalis, M. mulieris & C. albicans & HPV-16, HRC \\
\hline 9 & C. trachomatis, U urealyticum/parvum & - & GBS & HRC, HPV-18 \\
\hline 10 & M. hominis, U urealyticum/parvum, M. genitalium & - & GBS & HPV-16 \\
\hline 11 & - & $\begin{array}{l}\text { T. vaginalis, G. vaginalis, } \\
\text { B. fragilis }\end{array}$ & C. albicans & HRC, HPV-18 \\
\hline 12 & N. gonorrhoeae & T. vaginalis, G. vaginalis & C. glabrata & HPV-18 \\
\hline
\end{tabular}

HRC: HPV high-risk common 11 types.

\section{Comparison between HPV Multiplex PCR, HC2, and Microarray}

Overall, there are good agreements between methods to detect HPV, and multiplex PCR showed the highest agreement ratio with relation to direct sequencing (PCR vs. sequence, Kappa $=0.8558 ; \mathrm{HC} 2$ vs. sequence, Kappa = 0.8156; Chip vs. sequence, Kappa $=0.8539$; PCR vs. HC2, Kappa $=0.7179 ;$ PCR vs. Chip, Kappa $=0.8082$; HC2 with chip, Kappa = 0.7915;).

Because HC2 detects only HR group, 11 specimens with LR-HPV infection were excluded in the analytic sensitivity/specificity. The results of 25 of 235 specimens (10.6\%) were discordant among methods; therefore these specimens were analyzed by direct sequencing. DNA chip produced more false negative results than HPV multiplex PCR and HC2 did (Table 2).

Performance characteristics of the diagnostic test are shown in Table 3. Positive predictive values associated with multiplex PCR and microarray were greater than 90\%; the negative predictive value and accuracy rates were greater than 95\%. HPV multiplex PCR and DNA microarray methods showed analytical sensitivities greater than $85 \%$, and analytical specificity was nearly $100 \%$ with all methods. The area under the curve (AUC) was the highest for multiplex PCR at 0.922 . Receiver operating characteristics (ROC) are shown in Fig. 2. However, there were no statistically significant differences between the three methods tested.

\section{Analysis of the correlation between STIs and HPV infection}

Specimens positive for LR-HPV infection were frequently co-infected with $C$. trachomatis (4/18 HPV LR+ [22.2\%]; $\mathrm{p}=0.049)$, whereas those with HR-HPV were frequently detected with GBS (6/37 HPV HR+ [16.2\%]; p = 0.016).

\section{Discussion}

Reports of the incidence of STIs in asymptomatic women are not currently available, because of few attempts to recognize STI species despite advanced techniques based on liquid-based cytology [9-13].

We found that the overwhelming majority of patients with negative cytologic findings were positive for at least one STI (97.9\%); many were positive for multiple infectious agents (84.9\%). These results are surprising in that we did not observe high rates of infection with microbes that are typically widespread, such as $N$. gonorrhea and C.trachomatis [10,13]. In more than $25 \%$ of the samples, we detected microbes that cause asymptomatic, dormant non-gonococcal and non-chlamydial infections, such as $G$. vaginalis, $U$. urealyticum, Group $\beta$ streptococcus, and $M$. hominis. Microbes detected in less than $2 \%$ of the specimens were $C T-1, N G$, and $C$. parapsilosis (CP) [13]. $M H$ was often detected in the same sample with other microbes, such as UU, M. mulieris (MM), M. curtisii $(M C)$, and $C T$. However, co-infection of multiple mycoplasma strains has rarely been reported [15]. 
Table 2 Comparison of PCR, HC2, and Chip methods in 25 discordant samples

\begin{tabular}{|c|c|c|c|c|c|c|}
\hline & PCR & $\mathrm{HC2}$ & Chip & Sequence & False + & False - \\
\hline 1 & $L R$ & $\mathrm{~N}$ & $N$ & $\mathrm{~N}$ & PCR & \\
\hline 3 & $L R$ & $\mathrm{~N}^{* *}$ & $N$ & 70 & $\mathrm{PCR}^{1 *}$ & Chip \\
\hline 4 & $\mathrm{~N}$ & $\mathrm{HR}$ & $\mathrm{N}$ & 53 & $\mathrm{HC2}^{2 *}$ & PCR/Chip \\
\hline 5 & $\mathrm{HR}$ & $\mathrm{HR}$ & $\mathrm{N}$ & 66 & $\mathrm{HC2}^{3 *}$ & Chip \\
\hline 6 & $\mathrm{HR}$ & $\mathrm{HR}$ & $\mathrm{N}$ & 54 & $\mathrm{PCR} / \mathrm{HC2}$ & Chip \\
\hline 7 & $L R$ & $\mathrm{HR}$ & $\mathrm{N}$ & 11 & $\mathrm{HC2}$ & Chip \\
\hline 8 & $\mathrm{~N}$ & $\mathrm{HR}$ & OTHER & 83 & $\mathrm{HCl}^{\mathbf{4 *}}$ & $P C R^{4 *}$ \\
\hline 9 & $\mathrm{~N}$ & $\mathrm{HR}$ & OTHER & 52 & Chip: mistyping & PCR \\
\hline 10 & $\mathrm{~N}$ & $\mathrm{HR}$ & OTHER & $\mathrm{N}$ & HC2/Chip & \\
\hline 11 & $\mathrm{~N}$ & $\mathrm{HR}$ & $\mathrm{N}$ & 39 & & PCR/Chip \\
\hline 12 & $\mathrm{HR}$ & $N^{* *}$ & 70 & 70 & PCR & \\
\hline 13 & $\mathrm{~N}$ & $\mathrm{HR}$ & 16 & 16 & & PCR \\
\hline 14 & $\mathrm{HR}$ & $\mathrm{N}$ & 51 & 51 & & $\mathrm{HC2}$ \\
\hline 15 & $\mathrm{HR}$ & $N^{* *}$ & 11 & 11 & PCR & \\
\hline 16 & $\mathrm{HR}$ & $N^{* *}$ & 70 & 70 & PCR & \\
\hline 17 & $\mathrm{~N}$ & $\mathrm{HR}$ & $16+39$ & $16+39$ & & $\mathrm{HC2}$ \\
\hline 18 & $\mathrm{~N}$ & $\mathrm{HR}$ & 54 & 54 & $\mathrm{HC}^{5 *}$ & $P C R^{5 *}$ \\
\hline 19 & $\mathrm{~N}$ & $\mathrm{HR}$ & $\mathrm{N}$ & $\mathrm{N}$ & & $\mathrm{HC2}$ \\
\hline 20 & $\mathrm{HR}$ & $\mathrm{HR}$ & 70 & 70 & $P C R$ & $\mathrm{HC2}$ \\
\hline 21 & $\mathrm{~N}$ & $\mathrm{HR}$ & $\mathrm{N}$ & $\mathrm{N}$ & $\mathrm{HC2}$ & \\
\hline 22 & $\mathrm{~N}$ & $\mathrm{HR}$ & other & $\mathrm{N}$ & HC2/Chip & \\
\hline 23 & $18+\mathrm{HR}$ & $\mathrm{N}$ & $18+70$ & $18+70$ & & $\mathrm{HC2}$ \\
\hline 24 & $\mathrm{HR}+\mathrm{LR}$ & $\mathrm{N}$ (equivocal) & $73+43$ & $73+43$ & & $\mathrm{HC2}$ \\
\hline 25 & $\mathrm{HR}$ & $\mathrm{N}$ & 51 & 51 & & $\mathrm{HC2}$ \\
\hline
\end{tabular}

PCR (20 types; 18 HR types+2 LR types): 16, 18, 26, 31, 33, 35, 39, 45, 51, 52, 53, 56, 58, 59, 66, 68, 73, and $82+6$ and 11.

HC2: (13 HR types) $16,18,31,33,35,39,45,51,52,56,58,59$, and 68 .

Chip (26 types; 18 HR types+8 LR types): $16,18,26,31,33,35,39,45,51,52,56,58,59,66,68,69,73,53$ and LR: 70, 6, 11, 32, 34, 40, 42, 43, 44, 54, 55, $57,61,62$.

1*: PCR LR does not cover HPV-70 type.

2*: HC2 HR does not cover HPV-53 type.

3*: HC2 HR does not cover HPV-66 type.

4*: HC2 and PCR PR do not cover HPV-83 type.

5*: PCR LR does not cover HPV-54 type.

6*: PCR LR does not cover HPV-67 type.

**: HR2 was not considered in this analysis because HR2 excludes LR HPV types.

Because HPV and STIs rely on the same route of infection, this increased risk of HPV infection in patients with STIs was expected. Studies of women visiting STD clinics have reported a greater prevalence of HPV infection in this group than in the general population $[16,17]$. In one study, approximately half of the women evaluated at an STD clinic were infected with genital HPV, including HPV types-16, 83, 56, 52, and 59 (HR group) and 66 (LR group) [16]. In the present study of 235 asymptomatic women who had negative cytology results, we found that approximately $20 \%$ were infected with HPV. Using a genotyping microarray or grouping multiplex PCR, the most common HR types we detected were HPV types-16, 18, 51, 58, and 33, and the most common LR type was HPV-70. Epidemiologic data concerning HPV-types differ based on the method of detection used and the target samples. Multiple infections with more than two different HPV genotypes were found in $22 \%$ to $26 \%$ of the specimens, and HPV- 16 was most detected (50\%).

Specimens infected with LR-HPV were frequently coinfected with $C T$, whereas those with HR-HPV were coinfected with $G B S$. The fact that $C T$ associates with LR-HPV rather than HR-HPV suggests that CT is less likely to contribute to cervical intraepithelial neoplasia or squamous cell carcinoma. Previous reports suggested that coinfection with $C T$ and HPV is common in ASCUS and could contribute to the development of intraepithelial lesions [18-24]. It is possible that the modulation of cervical immune responses in response to 
Table 3 Efficacy of multiplex-HPV PCR, HC2, and Chip, based on direct sequencing

\begin{tabular}{|c|c|c|c|c|c|c|c|}
\hline & True Positive & True Negative & False Positive & \multicolumn{2}{|c|}{ False Negative } & \multicolumn{2}{|c|}{ HPV-all- Negative } \\
\hline PCR & 48 & 175 & 5 & \multicolumn{2}{|c|}{7} & \multicolumn{2}{|c|}{235} \\
\hline $\mathrm{HC2}$ & 45 & 173 & 6 & \multicolumn{2}{|c|}{9} & \multicolumn{2}{|c|}{233} \\
\hline \multirow[t]{2}{*}{ Chip } & 47 & 176 & 4 & \multicolumn{2}{|c|}{8} & \multicolumn{2}{|c|}{235} \\
\hline & Sensitivity & Sensitivity-I & Sensitivity-u & Specificity & Specificity-I & Specificity-u & AUC \\
\hline PCR & 87.2727 & 78.4646 & 96.0808 & 97.2222 & 94.8214 & 99.6230 & 0.922 \\
\hline $\mathrm{HC2}$ & 83.3333 & 73.3932 & 93.2735 & 96.6480 & 94.0113 & 99.2848 & 0.900 \\
\hline \multirow[t]{2}{*}{ Chip } & 85.4545 & 76.1369 & 94.7722 & 97.7778 & 95.6243 & 99.9312 & 0.916 \\
\hline & PPV & PPV-I & PPV-u & NPV & NPV-I & NPV-u & Accuracy \\
\hline PCR & 90.5660 & 82.6965 & 98.4356 & 96.1538 & 93.3599 & 98.9478 & 94.8936 \\
\hline $\mathrm{HC2}$ & 88.2353 & 79.3926 & 97.0779 & 95.0549 & 91.9051 & 98.2048 & 93.5622 \\
\hline Chip & 92.1569 & 84.7782 & 99.5356 & 95.6522 & 92.7055 & 98.5988 & 94.8936 \\
\hline
\end{tabular}

-I: lower limit of $95 \%$ confidence interval, -u: upper limit of $95 \%$ confidence interval.

AUC: area under the curve.

PPV: positive predictive value,

NPV: negative predictive value.

CT may influence the clearance of HPV lesions [18,19], and suggesting that $C T$ infection with HPV persistence is not a coincidence [20]. Likewise, we are the first to document the prevalence of coinfection of GBS and HRHPV in negative cytology (including RCC and ASCUS). However, it remains uncertain that GBS may be an independent factor or cofactor for HPV in the development of cervical intraepithelial neoplasm. For identification of its cofactor, novel immune evasion strategies and the analysis of their functions in the context of viral and bacterial infections should be required in further studies.

We compared high-throughput HPV detection methods in the present study, and found that discrepancies with direct sequencing were observed only in $10.6 \%$.

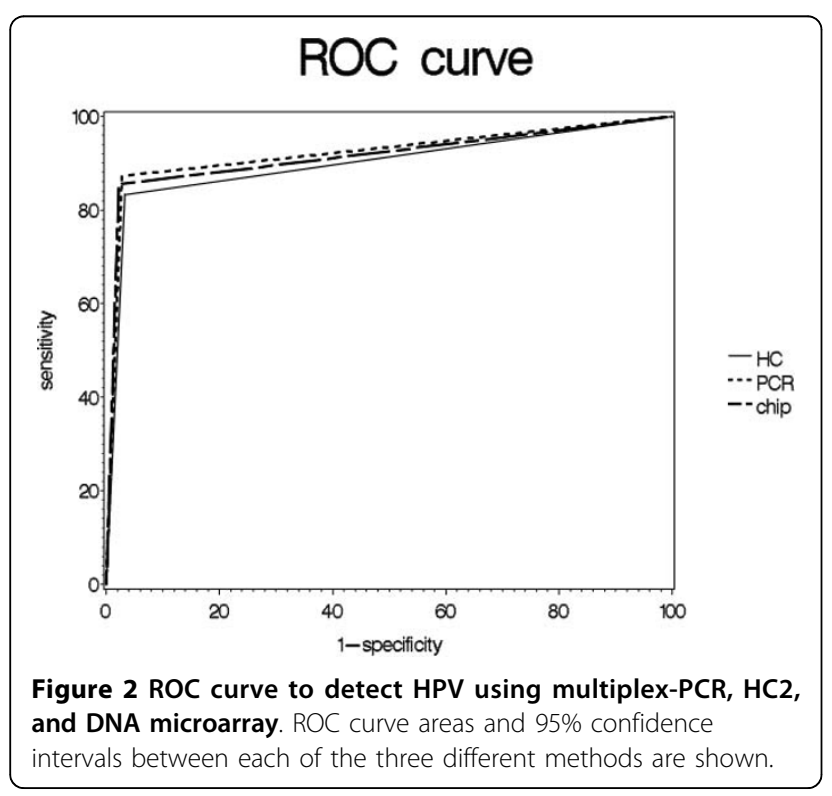

The microarray (DNA chip) method also resulted in a significant number of false negative results. Analysis of 25discordant samples showed that multiplex PCR-HPV method exhibited the highest sensitivity, positive predictive value, and accuracy. However, each HPV detection method covered different genotypes, and different typing or grouping methods were used to present the data. For example, the relatively low sensitivity of $\mathrm{HC} 2$ may be due to its inability to detect LR genotypes, and its lower positive predictive values and accuracy may be due to limitations in detecting individual genotypes, and thus, multiple infections.

\section{Conclusions}

In conclusion, asymptomatic women of reproductive age with negative cytologic findings had a high frequency of infection with $G V, U U, G B S$, and $M H$. Most HPV infections were not associated with any specific STI pathogen; however, LR-HPV infection correlated with $C T$ infection, and HR-HPV with GBS infection. In terms of sensitivity and prediction value, multiplex PCR yielded data most similar to that of DNA microarray.

\section{Short Summary}

Two hundred thirty-eight asymptomatic women of reproductive age with negative cytology had high frequency of sexually-transmitted infection (96.6\%), and 24.4\% had HPV.

\section{Additional material}

Additional file 1: Summarized data of target organisms, target genes, accession numbers, and the expected amplicon sizes. Primers were designed such amplicon sizes differed sufficiently to be

distinguished from each other; they ranged from $212 \mathrm{bp}(U U)$ to $635 \mathrm{bp}$ (CG) and the internal control was $981 \mathrm{bp}$. 


\section{Acknowledgements}

This study was supported by the Korea Healthcare Technology R\&D Project, Ministry for Health, Welfare and Family Affairs, Republic of Korea (CNH: A084550), and Mid-career Researcher Program through NRF grant funded by the MEST (No. 2010-0000357; CNH)

\section{Author details}

'Department of Pathology, Yonsei University College of Medicine (Sungsanro 134), Seoul (120-752), South Korea. ${ }^{2}$ Department of Affairs of Research Biostatistic, Yonsei University College of Medicine (Sungsanro 134), Seoul (120-752), South Korea. ${ }^{3}$ Seegene Institute of Life Science (Taewon Bldg, 655), Seoul (138-050), South Korea. ${ }^{4}$ Brain Korea 21 Project for Medical Science, Yonsei University (Sungsanro 134), Seoul (120-752), South Korea.

\section{Authors contribution}

HSS and SMN summarized, analyzed data and equally drafted entire manuscript. ARP performed statistical analysis of given data. YNL \& KSK participated in cytology screening and sample preparation with performance of HC2/DNA microarray. JKK \& HJC performed multiplex PCR. NHC designed and participated in DNA direct sequencing, and revised manuscript. All authors read and approved the final manuscript.

\section{Competing interests}

The authors declare that they have no competing interests.

Received: 30 November 2009 Accepted: 28 September 2010 Published: 28 September 2010

\section{References}

1. Schmitt CS: Global epidemiology of sexually transmitted diseases. Asian J of Androl 2008, 10:110-114.

2. Mayar R, Wilbur DC, Solomon D: The Bethesda system for reporting cerical cytology. In Comprehensive Cytopathology. Edited by: Bibbo M Wilbur D. Philadelphia: Saunders; , 3 2008:77-90.

3. Boon HE, Gray W: Normal vulva, vagina and cervix: hormonal and inflammatory conditions. In Diagnostic Cytopathology. Edited by: Gray W, McKee GT. London: Churchill Livingstone; 2 2003:651-705.

4. Boris $S$, Suarez JE, Vazquez E, Barbes C: Adherence of human vaginal lactobacilli to vaginal epithelial cells and interaction with uropathogens. Infect Immun 1998, 66:1985-1989.

5. McLean NW, Rosenstein IJ: Charaterization and selection of a Lactobacillus species to re-colonize the vagina of women with recurrent bacterial vaginosis. J Med Microbiol 2000, 49:543-552.

6. Judlin P: Genital mycoplasmas. Gynecol Obstet Fertil 2003, 31:954-959

7. Taylor-Robinson D, Furr PM: Genital mycoplasma infection. Wien Klin Wochenschr 1997, 109:578-583.

8. Unskula A, Kohl PK: Genital mycoplasmas, including Mycoplasma genitalium, as sexually transmitted agents. Int J STD and AIDS 2002, 13:79-85.

9. Rager KM, Biro FM: Techniques of testing for sexually transmitted diseases. Curr Womens Health Rep 2001, 1:111-115.

10. Garland SM, Tabrizi SN, Chen S, Byambaa C, Davaajav K: Prevalence of sexually transmitted infections (Neisseria gonorrhoeae, Chlamydia tranchomatis, Trichomonas vaginalis and human papillomavirus) in female attendees of a sexually transmitted diseases clinic in Ulaanbaatar, Mongolia. Infec Dis Obstet Gynecol 2001, 9:143-146.

11. Boyer CB, Shafer MA, Pollack LM, Canchola J, Moncada J, Schachter J: Sociodemographic markers and behavioral correlates of sexually transmitted infections in a nonclinical sample of adolescent and young adult women. J Infect Dis 2006, 194:307-315.

12. Rompalo AM, Gaydos CA, Shah N, Tennant M, Crotchfelt KA, Madico G, Quinn TC, Daniel R, Shah KV, Gaydos JC, McKee KT Jr: Evaluation of use of a single intravaginal swab to detect multiple sexually transmitted infections in active-duty military women. Clin Infect Dis 2001, 33:1455-1461

13. Marrazzo JM: Impact of new sexually transmitted disease diagnostics on clinical practice and public health policy. Curr Infect Dis Rep 2001, 3:147-151

14. Gustavsson I, Juko-Pecirep I, Backlund I, Wilander E, Gyllensten U: Comparison between the hybrid capture 2 and hpVIR real-time PCR for detection of human papillomavirus in women with ASCUS or low grade dysplasia. J Clin Virol 2009, 45:85-89.

15. Yokoi S, Maeda S, Kubota Y, Tamaki M, Mizutani K, Yasuda M, Ito S, Nakano M, Ehara H, Deguchi T: The role of Mycopalsma genitalium and Ureaplasma urealyticum Biovar 2 in postgonococcal urethritis. Clin Infect Dis 2007, 45:866-871.

16. Brown DR, Legge D, Qadadri B: Distribution of human papillomavirus types in cervicovaginal washings from women evaluated in a sexually transmitted diseases clinics. Sex Trans Dis 2002, 29:763-768.

17. Svare El, Kjaer SK, Worm AM, Osterlind A, Moi H, Christensen RB, Meijer CJ, Walboomers JM, van den Brule AJ: Risk factors for HPV infection in women from sexually transmitted disease clinics: comparison between two areas with different cervical cancer incidence. Int J Cancer 1998, 75:1-8.

18. Verteramo R, Pierangeli A, Mancini E, Calzolari E, Bucci M, Osborn J, Nicosia R, Chiarini F, Antonelli G, Degener AM: Human papillomaviruses and genital co-infection in gynecological outpatients. BMC Infect Dis 2009, 9:16-23.

19. Simonetti AC, de Lima Melo JH, de Souza PRE, Bruneska D, de Lima Filho JL: Immunological's host profile for HPV and Chlamydia trachomatis, a cervical cancer cofactor. Microbes and Infection 2009, 11:435-442.

20. Silins I, Ryd W, Strand A, Wadell G, Törnberg S, Hansson BG, Wang X, Arnheim L, Dahl V, Bremell D, Persson K, Dillner J, Rylander E: Chlamydia trachomatis infection and persistence of human papillomavirus. Int $J$ Cancer 2005, 116:110-115.

21. de Paula FDF, Fernandes AP, do Carmo BB, Vieira DC, Dutra MS, Santos CG, Souza Mdo C, Andrade TC, Vago AR, Fernandes PA: Molecular detection of Chlamydia trachomatis and HPV infections in cervical samples with normal and abnormal cytopathological findings. Diagn Cytopathol 2007, 35:198-202.

22. Lehmann M, Groh A, Rodel J, Nindl I, Straube E: Detection of Chlamydia trachomatis DNA in cervical samples with regard to infection by human papillomavirus. J Infect 1999, 38:12-17.

23. Keegan H, Ryan F, Malkin A, Griffin M, Lambkin H: Chlamydia trachomatis detection in cervical PreserCyt specimens from an Irish urban female population. Cytopathology 2009, 20:111-116.

24. Denks K, Spaeth EL, Joers K, Randoja R, Talpsep T, Ustav M, Kurg R: Coinfection of Chlamydia trachomatis, Ureaplasma urealyticum and human papillomavirus among patients attending STD clinics in Estonia. Scand J Infect Dis 2007, 39:714-718.

\section{Pre-publication history}

The pre-publication history for this paper can be accessed here: http://www.biomedcentral.com/1471-2334/10/284/prepub

\section{doi:10.1186/1471-2334-10-284}

Cite this article as: Shim et al:: Detection of sexually transmitted infection and human papillomavirus in negative cytology by multiplexPCR. BMC Infectious Diseases 2010 10:284.

\section{Submit your next manuscript to BioMed Central and take full advantage of:}

- Convenient online submission

- Thorough peer review

- No space constraints or color figure charges

- Immediate publication on acceptance

- Inclusion in PubMed, CAS, Scopus and Google Scholar

- Research which is freely available for redistribution 